\title{
Depression and loneliness in Jamaicans with sickle cell disease
}

\author{
Monika R Asnani", Raphael Fraser, Norma A Lewis, Marvin E Reid
}

\begin{abstract}
Background: Sickle cell disease (SCD) is the commonest genetic disorder in Jamaica, and has life-long implications for those afflicted with it. It is well known that depression and loneliness may exist in those with chronic diseases, but the coexistence of depression and loneliness in people with sickle cell disease is not clear. The aim of this study is to determine the prevalence of and factors associated with depression and loneliness in the Jamaica Sickle Cell Cohort Study and its age and sex matched controls.

Methods: 277 patients with SCD and 65 controls were administered a questionnaire that studied demographics, disease severity, depression, and loneliness. Regression analyses were done to examine relationships between outcomes and associated variables.

Results: Depression was found in $21.6 \%$ of patients and $9.4 \%$ in controls. Loneliness scores were also significantly higher in patients $(16.9 \pm 5.1)$ than in controls (14.95 \pm 4.69$)$. Depression was significantly associated with unemployment $[\mathrm{OR}=2.9$, $\mathrm{p}$-value: $<0.001]$, whereas unemployment ( $\mathrm{p}$-value: 0.002 ), and lower educational attainment were significantly associated with loneliness.

In patients with SCD, depression was significantly associated with being unemployed (OR 2.4, 95\% Cl 1.2,4.6, pvalue:0.01), presence of a leg ulcer $(\mathrm{OR}=3.8,95 \% \mathrm{Cl}: 1.7,8.4, \mathrm{p}$-value: 0.001$)$, frequent visits $(\mathrm{OR}=3.3,95 \% \mathrm{Cl}: 1.2$, 8.9, p-value: 0.019), and frequent painful crises ( $\mathrm{OR}=2.5,95 \% \mathrm{Cl}: 1.1,5.8, \mathrm{p}$-value: 0.035$)$. Not being employed (Coef.: 2.0; p-value: 0.004) and higher educational attainment (tertiary vs. primary education, Coef.: -5.5; p-value: < 0.001) were significant associations with loneliness after adjusting for genotype.
\end{abstract}

Conclusions: Health workers need to actively look for and manage these problems to optimize their patients' total biopsychosocial care.

\section{Background}

Sickle Cell Disease (SCD) is a chronic and potentially, quite a debilitating disease. The disease is severe and may result in significant morbidity, as well as a shortened life span. There is considerable variability in the clinical course of sickle cell disease with some patients experiencing few to no complications and others having multiple organ involvement [1]. Painful crises, lung diseases such as Acute Chest Syndrome, leg ulcerations, and priapism are common complications of the disease in Jamaica. These and other complications contribute a lot to the social isolation and lack of normal functioning in these patients.

\footnotetext{
* Correspondence: monika.parshadasnani@uwimona.edu.jm Sickle Cell Unit, Tropical Medicine Research Institute, University of the West Indies, Mona Campus, Kingston 6, Jamaica (W.I
}

Depression is one of the most common complications of chronic illnesses [2-4]. According to one survey [2], depression was found to be common in patients diagnosed with: recent heart attacks (45\%), hospitalized cancer patients (42\%), recent stroke survivors $(40 \%)$, and people with multiple sclerosis $(40 \%)$, Parkinson's disease (40\%), and diabetes (33\%). Depression caused by chronic illness often aggravates the illness, especially if the condition causes pain, fatigue, or disruption of social life.

The prevalence of depression in SCD patients has been reported to be high [5-9]. The Pain in Sickle Cell Epidemiology Study has also shown the prevalence of depression (as assessed by studying daily diaries) to be a high of 27.6\% [10]. Hilton et al (1997) have reported on the prevalence of overall psychiatric morbidity in patients with SCD in Jamaica but not of depression [11]. 
Loneliness is a measure of being cut off or separated from others. It refers to a deficiency of social contact compared to what is desired [12], and is fundamentally an aversive and distressing experience with potentially serious consequences [13]. As such it is a distinct psychological problem from depression. Loneliness has been linked to a number of somatic and psychological difficulties and has been associated with lower reported life satisfaction, suicide and alcoholism [14]. A few studies have shown loneliness to be increased in patients with acute or chronic diseases [15-17]. Loneliness and depression also have been found to co-exist in a number of populations [18-20]. In SCD, depression and loneliness may be as a result of living with a chronic disease itself, or may be a result of societal and health care providers' response to these persons [9,21].

No studies have looked at the co-existence of depression and loneliness in SCD and it is hypothesized that depression and loneliness will have a high prevalence and coexist in this population. In this study therefore, we have sought to determine the prevalence of depression and loneliness in a birth cohort of patients with SCD in Jamaica and compare it to its age- and sexmatched set of controls. We have also sought to determine possible socioeconomic and clinical factors associated with depression and loneliness in this disease group.

\section{Methods}

\section{Sampling}

The Jamaica Sickle Cell Cohort Study (JSCCS) incorporates all patients with SCD detected during the screening of 100,000 consecutive deliveries at the Victoria Jubilee Hospital - the country's main government maternity hospital - from June 1973 to December 1981. This screening identified 552 cases with SCD, 315 children with homozygous sickle cell (SS) disease, 178 with sickle cell-haemoglobin C (SC) disease, 33 with sickle cell-beta + thalassaemia (S beta + thal) and 14 with sickle cellbeta $^{0}$ thalassaemias ( $\mathrm{S}$ beta $^{0}$ thal). These patients have been closely followed since birth and are seen at the only comprehensive sickle cell clinic (SCU) located at the University of the West Indies in Kingston, Jamaica for routine health maintenance checks and for all significant sick events in an effort to document the natural history of the disease. They are actively located if they have not presented to the SCU for more than 6 months1 year. 277 patients were available (the rest having been lost mainly to emigration and death), and all took part in the study where they were administered the study questionnaire comprising questions on socio-demographics, disease severity, depression and loneliness.

At the initial recruitment of the JSCCS, the first 125 SS babies were each matched with two controls with an
AA phenotype of the same sex born closest in time (usually immediately before and after) resulting in 250 controls collected over the first $21 / 2$ years. 64 of these controls are still available and were also administered the questionnaire including questions on socio- demographics, depression and loneliness.

\section{Data collection}

The demographic data collected included age, sex, marital status, genotype, employment status, and the highest educational level they had attained. Questions were also included on their utilization of the clinic (SCU) services, frequency of painful crises, and whether they had leg ulceration as a result of their sickle cell disease. Pain was defined as 'severe bony pains requiring opiod analgesia for relief', and was categorized as being 'Rare' if they rarely had bony pains or 'Frequent' if they suffered a painful crisis at least once monthly. Similarly, utilization of the clinic services was categorized as ' $\leq 1-3$ times/year' (Rare) or ' $\geq$ once/month' (Frequent). Depression was measured using the 21-point Beck Depression Inventory-version II (BDI), and loneliness using the UCLA-8 Loneliness scale (UCLA).

\section{Beck Depression Inventory-II}

The BDI is one of the most commonly utilized measure of depression among adolescents and adults by clinicians and researchers alike [22]. The BDI-II has demonstrated high internal consistency, good test-retest reliability, and good construct and concurrent validity with other common measures of depression in clinical and nonclinical samples [23]. Discriminant validity has also been demonstrated through weaker relationships with measures of other psychopathology, such as anxiety [24]. In Jamaica, the BDI has been validated previously in a sample of university students [25].

\section{UCLA-8 Loneliness Scale}

A widely used loneliness measure is the UCLA loneliness scale developed by Russell \& colleagues [26,27]. Psychometric analyses including confirmatory factor analyses have confirmed that this is a reliable and valid measure of loneliness across a variety of populations [28-30]. Hays and DiMatteo [12] have developed an eight-item short form of the UCLA-20, the UCLA-8, which has been shown to be highly correlated with the original form $(r=0.91)$. Scores on the UCLA-8 are also well distributed, ranging from $0 \%$ to $100 \%$ of the maximum possible. The UCLA- 8 is a practical alternative to the UCLA-20 and reduces respondent burden. The latter may lead to improved quality of data being collected. Although the estimated reliability of the UCLA- 8 is a little lower than that of the UCLA-20, there is greater homogeneity in this measure [12]. Cross-cultural studies have shown the stability of the measure across countries and cultures $[31,32]$. 
The controls were given the questionnaire that included information only on socio-demographics as well as the BDI and UCLA. Both instruments showed acceptable internal consistency reliabilities in SCD (BDI: $\alpha=0.95$; UCLA: $\alpha=0.82$ ) as well as in the AA (BDI: $\alpha$ $=0.90$; UCLA: $\alpha=0.78$ ) group. Higher scores on the BDI and UCLA imply worsening depression and loneliness respectively.

Written, informed consent was obtained prior to administering the questionnaire that had been pretested. Complete confidentiality was maintained throughout the study. The study was granted ethical approval by the University of the West Indies/University Hospital of the West Indies Ethical Committee.

\section{Statistical analyses}

Descriptive statistics are reported as frequency and percent for categorical data and as mean and SD for continuous data. Continuous variables were compared by Student's $t$ test. Pearson correlations were used to assess linear associations between the two scales. Age, gender, highest educational level achieved, group (SCD vs. AA), employment status, frequency of visit to SCU, pain crises frequency and other symptoms characteristic of SCD were used as covariates in our regression models. Depression and loneliness were the outcomes of interest. The analyses were first done on the entire group then on the SCD subgroup. As the author Aaron Beck has stated that the BDI has no stringent cut-offs, a higher score of 17 was used to allow greater specificity to diagnosis. Also, in chronic illnesses that have somatic symptoms, the BDI may give falsely elevated scores [33,34], and as SCD does cause symptoms such as fatigue and loss of energy, a higher cut-off of 17 was utilized. Logistic regression was used to examine the relationship between independent variables and depression, and multivariate linear regression to examine the possible factors associated with loneliness. Data was analyzed using Stata Software version 10 for Windows ${ }^{\text {th }}$ (StataCorp, College Station, TX).

\section{Results}

The study sample consisted of 277 patients with SCD (mean age 31 years) and 65 patients with normal AA genotype (mean age 33.6 years), with equal proportions of males and females in each subgroup (Table 1). A significantly greater proportion of the controls had higher levels of educational attainment and was employed.

The mean depression score (9.19 \pm 10.4 , Range 0, 50) was significantly higher in SCD than in AA controls (6.4 \pm 7.9 , Range 0,41 ), with almost twice the proportions of SCD persons being depressed as compared to the controls. The mean loneliness score was also significantly higher in SCD $(16.9 \pm 5.1)$ than in AA controls (14.95 \pm
Table 1 Summary of patient characteristics

\begin{tabular}{|c|c|c|}
\hline & $\begin{array}{l}\text { SCD } \\
(N=277)\end{array}$ & $\begin{array}{l}\text { AA } \\
(\mathrm{N}=65)\end{array}$ \\
\hline Age in years, mean $(S D)^{* * *}$ & $31.0(2.50)$ & $33.6(0.67)$ \\
\hline Gender (female/male) & $140 / 137$ & $37 / 28$ \\
\hline Employment (yes/no)*** & $157 / 107$ & $58 / 7$ \\
\hline \multicolumn{3}{|l|}{ Educational status ${ }^{* *}$} \\
\hline Primary & 35 & - \\
\hline Secondary/High & 121 & 34 \\
\hline Post Secondary/Skills training & 84 & 18 \\
\hline Tertiary & 24 & 12 \\
\hline Depression score*, mean (SD) & $9.19(10.38)$ & $6.42(7.94)$ \\
\hline Proportion depressed* & $21.6 \%$ & $9.4 \%$ \\
\hline Loneliness score ${ }^{* *}$, mean (SD) & $16.94(5.10)$ & $14.95(4.69)$ \\
\hline
\end{tabular}

4.69). The Pearson's correlation between the two scales was 0.39 for those with SCD implying that the two scales were probably not measuring a similar concept.

The distribution of BDI scores in those with SCD is shown in Figure 1. Further comparisons were done within the SCD cohort to determine differences between those who were not depressed (BDI scores (mean $\pm \mathrm{SD}$ ): $4.6 \pm 4.7)$ and those depressed (BDI scores (mean $\pm \mathrm{SD}$ ): $25.8 \pm 8.2$ ) (Table 2). There were no differences in age, sex, genotype and marital status of those 'not depressed' and those 'depressed'. However, depressed patients had significantly lower levels of educational attainment ( $\mathrm{p}$ value 0.002 ) and more were unemployed ( $p$-value 0.001 ). Those depressed had worse disease as evidenced by having higher proportion of leg ulceration ( $\mathrm{p}$-value 0.006 ), higher frequency of painful crises ( $p$-value < 0.001 ) and more frequent visits to the SCU (p-value < 0.001). The depressed patients also had significantly higher mean loneliness scores (mean score: 16.1 vs. 20.1, p-value $<0.0001)$.

\section{Depression and loneliness}

The relationship between the various factors (age, gender, highest educational level achieved, group [SCD vs. AA], employment status) and depression was explored with a series of logistic regression models, and their relationship with loneliness was explored with multivariate linear regression. In the final model, not being employed was the only factor significantly associated with depression in the study sample $[\mathrm{OR}=2.9$ (95\% CI: $1.6,5.1) \mathrm{p}$-value: $<0.001]$, adjusting for presence of SCD (Table 3). Not being employed was also a significantly associated with loneliness (p-value: 0.002), whereas higher levels of educational attainment were associated with lower levels of loneliness (Table 4). Higher depression scores were associated with higher loneliness scores (regression coef.; 0.78; p value $<0.001$ ). 


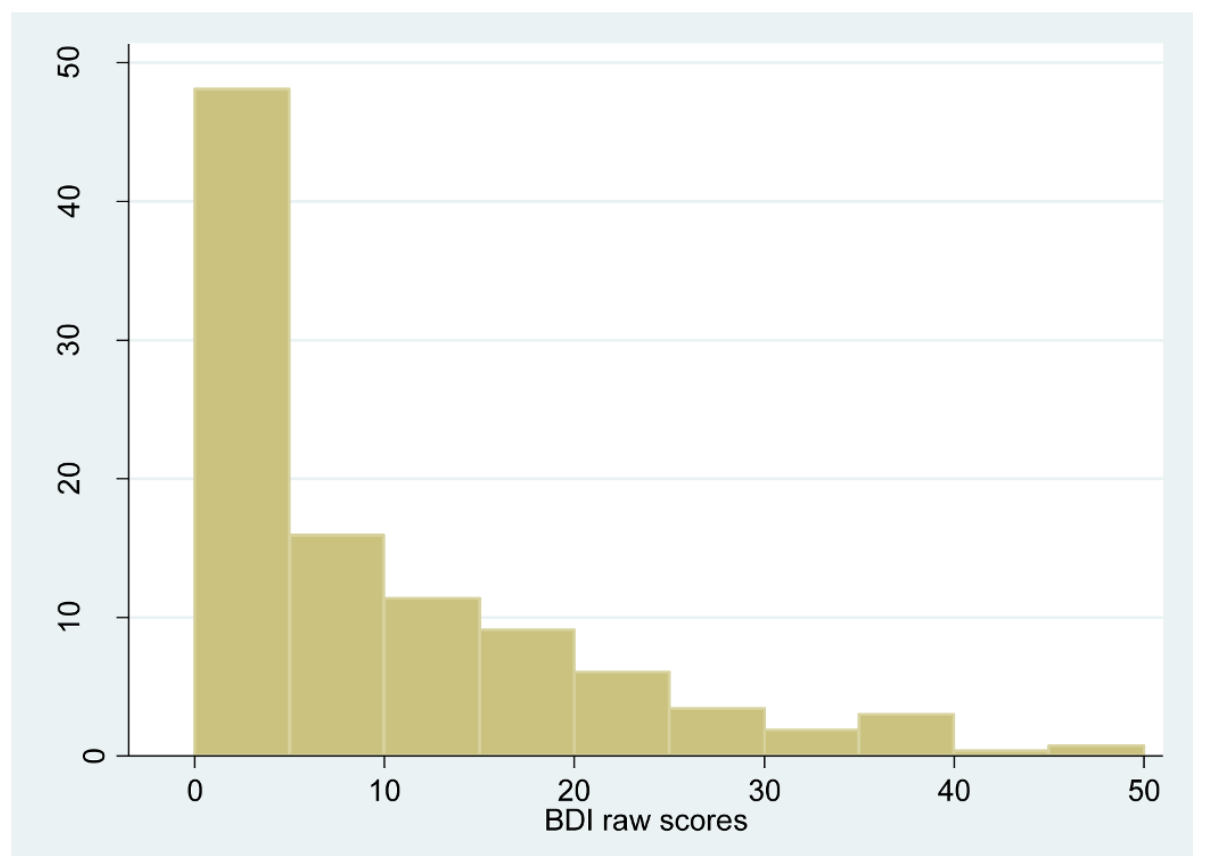

Figure 1 Distribution of BDI scores in SCD.

\section{Depression and loneliness in SCD}

The odds ratios (OR) for the factors that were significantly related to depression (Table 5), adjusting for genotype, were being unemployed (OR 2.4, 95\% CI 1.2,4.6, p-value:0.01), presence of leg ulcer (OR $=3.8$ (95\% CI: 1.7, 8.4, p-value: 0.001$)$, frequent visits to the sickle cell unit (OR $=3.3,95 \% \mathrm{CI}: 1.2,8.9$, p-value: 0.019$)$, and frequent painful crises $(\mathrm{OR}=2.5,95 \% \mathrm{CI}: 1.1,5.8, \mathrm{p}$-value: 0.035).

Multivariate linear regression yielded, once again, not being employed (Coef: 2.0, p-value: 0.004), and higher educational attainment (vocational/skills training compared to primary education Coef: -2.3 , p-value: 0.028 ; tertiary education compared to primary education, Coef: -5.5, p-value: < 0.001) as factors significantly associated with loneliness after adjusting for genotype (see Table 6).

\section{Discussion}

The primary aim of this study was to examine the prevalence of depression and loneliness in adult patients with Sickle Cell Disease in Jamaica and compare it to an age-matched set of controls.

Depression was found in a significantly higher proportion of patients with SCD $(21.6 \%)$ than in controls (9.4\%). The latter compares well to other studies that have shown the prevalence of depression in the general Jamaican population to be at $8 \%$ [35]. Previous studies [5] using the BDI have reported prevalence of depression in SCD to be at $44 \%$, but using a cut off score of 14. Wilson Schaeffer et al (1999) found the prevalence to be at $43.4 \%$, which fell to $18 \%$ using a more stringent cut-off. They used the Centre for Epidemiologic Studies - Depression scale (CES-D) as their tool and studied 440 adults. The mean age of this sample however, was much higher at $33.7(\mathrm{SD}=11.5)$. Most of previous studies possibly have a symptomatic bias attributable to the recruitment of patients from a clinic population. This is in contrast to our study where we have examined a well birth cohort of patients which has been followed up actively over the years. This has allowed for this study to include those people with SCD who tend to have good physical health.

Similarly, patients with SCD have shown higher levels of loneliness than their controls. To our knowledge, there are no previous reports of loneliness among this patient group. Loneliness seems to be strongly related to a broad range of negative emotional and cognitive states such as depression and anxiety [26], and it has been suggested that loneliness and depression may act synergistically to diminish well being [36]. Our study has also shown a moderately high correlation between loneliness and depression, and higher levels of loneliness among those who are depressed. Even though most studies on loneliness have been done in nursing home residents and the elderly, socially isolated young adults have shown higher rates of mortality $[37,38]$, even after adjusting for other risk factors for death. Lonelier 
Table 2 Sociodemographic and clinical variables in persons with SCD

\begin{tabular}{|c|c|c|c|}
\hline & Nil Depression & Depression & $\mathrm{p}$-value \\
\hline Age in years, mean(SD) & $30.9(2.5)$ & $31.1(2.5)$ & 0.582 \\
\hline Sex, Male:Female & 105:102 & $23: 34$ & 0.165 \\
\hline Genotype, n (\%) & & & 0.917 \\
\hline SS & $117(56.5)$ & $33(57.9)$ & \\
\hline SC & $64(31)$ & $18(31.6)$ & \\
\hline Others & $26(12.5)$ & $6(10.5)$ & \\
\hline Marital Status, n (\%) & & & 0.742 \\
\hline Single & $184(88.9)$ & $52(91.2)$ & \\
\hline Married & $21(11.1)$ & $5(8.8)$ & \\
\hline Educational Status, n (\%) & & & 0.002 \\
\hline Primary & $26(12.6)$ & $9(15.8)$ & \\
\hline Secondary/High & $85(41.0)$ & $36(63.2)$ & \\
\hline Vocation/Skills & $72(34.8)$ & $12(21.0)$ & \\
\hline Tertiary & $24(11.6)$ & $0(0)$ & \\
\hline Employment status, n (\%) & & & 0.001 \\
\hline Yes & $134(64.7)$ & $23(40.4)$ & \\
\hline No & $73(35.3)$ & 34 (59.6) & \\
\hline Leg Ulcers, n (\%) & & & 0.006 \\
\hline No & $175(84.5)$ & $39(68.4)$ & \\
\hline Yes & $32(15.5)$ & 18 (31.6) & \\
\hline Pain Category, n (\%) & & & $<0.001$ \\
\hline Rare & $180(87)$ & $36(63.2)$ & \\
\hline Frequent & $27(13)$ & $21(36.8)$ & \\
\hline Visits to SCU, n (\%) & & & $<0.001$ \\
\hline Rare ( $\leq 1-3$ times/year) & $192(92.8)$ & $42(73.7)$ & \\
\hline Frequent ( $\geq$ Once/month) & $15(7.2)$ & $15(26.3)$ & \\
\hline Loneliness Score, mean (SD) & $16.1(4.8)$ & $20.1(5.2)$ & $<0.0001$ \\
\hline
\end{tabular}

Table 3 Predictors of depression adjusting for presence of disease (SCD + AA)

\begin{tabular}{llll}
\hline Variable & OR & $\mathbf{9 5 \%} \mathbf{C l}$ & p-value \\
\hline Not employed & 2.9 & $1.6,5.1$ & $<0.001$ \\
Presence of SCD & 1.9 & $0.8,4.8$ & 0.17 \\
\hline
\end{tabular}

persons have shown lower cardiovascular function (higher total peripheral resistance and lower cardiac output) [39], as well as lower immune and higher stress levels [40]. It remains to be seen if loneliness may lower immune response, cardiovascular resilience, etc. in patients with SCD.
Table 4 Predictors of loneliness adjusting for presence of disease (SCD+AA)

\begin{tabular}{llll}
\hline Variable & Coefficient & $\mathbf{9 5 \% ~ C l}$ & p-value \\
\hline Not employed & 1.96 & $0.7,3.2$ & 0.002 \\
*Education level & & & \\
$\quad$ Vocation/Skills & -2.2 & $-4.2,-0.24$ & 0.03 \\
$\quad$ Tertiary & -6.4 & $-9.0,-3.8$ & $<0.001$ \\
Presence of SCD & 0.66 & $-0.7,2.1$ & 0.35 \\
\hline
\end{tabular}

*Compared to 'Primary education'

Table 5 Predictors of depression in SCD adjusting for genotype

\begin{tabular}{llll}
\hline Variable & OR & $\mathbf{9 5 \% ~ C l}$ & p-value \\
\hline Not employed & 2.4 & $1.2,4.6$ & 0.010 \\
Presence of leg ulcers & 3.8 & $1.7,8.4$ & 0.001 \\
*Frequent visits to the unit & 3.3 & $1.2,8.9$ & 0.019 \\
( $\geq$ once/month) & & & \\
**Frequent pains ( $\geq$ once monthly) & 2.5 & $1.1,5.8$ & 0.035 \\
***SC genotype & 2.5 & $1.1,5.4$ & 0.027 \\
\hline
\end{tabular}

- ${ }^{*}$ Compared to 'Visits 1-3 times a year';

- ** Compared to 'Rare pains';

. ***Compared to 'SS genotype'

Table 6 Predictors of loneliness in SCD adjusting for genotype

\begin{tabular}{llll}
\hline Variable & Coefficient & $\mathbf{9 5 \% ~ C l}$ & p-value \\
\hline Not employed & 2.0 & $0.6,3.4$ & 0.004 \\
*Education level & & & \\
$\quad$ Vocation/Skills & -2.3 & $-4.4,-0.3$ & 0.028 \\
$\quad$ Tertiary & -5.5 & $-8.4,-2.5$ & $<0.001$ \\
\hline
\end{tabular}

*Compared to 'Primary education'

It is important to note that lack of employment was a significant factor associated with higher levels of depression and loneliness irrespective of having SCD or not. Also, those with lower levels of educational attainment tended to be lonelier. Previous studies have also confirmed that poorer social and economic circumstances lead to higher levels of depression, as well as worse disease outcomes $[8,10,41]$. It is important against this background that health care professionals remain vigilant to proper school attendance and educational attainment of young children with SCD, so as to enable them for better employment opportunities in the future.

\section{Depression, loneliness and SCD}

Another aim of the study was to examine variables that were significantly associated with depression and loneliness in those with SCD. Being unemployed, having leg ulcerations, more frequent painful crises, and frequently visiting SCU for health care were all positively associated with depression in those with SCD. Once again, 
unemployment and lower educational attainment were associated with greater loneliness scores among this disease population. Gender, age and marital status have shown no associations with either of these outcomes.

More frequent painful crises and visiting the unit more frequently were positively associated with depression. Depressive symptoms often complicate chronic pain, and may lower the threshold and tolerance for pain. These observations have been consistent in previous studies $[5,8,10,42]$. Our study has also shown leg ulceration to be significantly associated with depression and it was a frequent complication of SCD in this study population (18.9\%). Although leg ulceration is not a complication that is associated with high mortality in $\mathrm{SCD}$, it is a frequent and chronic condition that leads to a huge degree of morbidity especially in younger people with SCD [43]. These persons have also been shown to have lower educational attainment and inability to form stable marital relations [44].

A surprising finding from this study was the fact that heterozygous SC disease (as compared to SS Disease) was significantly associated with greater depression (OR 2.5, 95\% CI 1.1,5.4, p-value:0.027), even though both SS and SC have demonstrated same frequency of depression (22\%) in this study sample. This is despite the fact that those with SC disease were more likely to be employed, and had less severe disease as evidenced by less frequent visits to the unit, less frequent painful crises and lower prevalence of leg ulceration (results not shown). This finding may point to lower coping mechanisms in those with the less severe form of disease; past findings have also similarly pointed to greater psychological distress among those with milder genotypes of SCD $[8,45]$. Severity of disease is not always correlated to psychological adjustment or coping, and maybe those with more severe illness have better social support systems and may have learnt better stress-management strategies to help them with their illness [45]. Further studies would enable us to gain understanding into mechanisms of depression in this disease population and how these may vary among different genotypes.

The main limitations of this study relate to the instrument used to assess depression and the characteristics of the sample studied. Even though the BDI is a valid instrument [46] for measuring the degree of depression, a structured clinical interview would have been more diagnostic. The second limitation is that the study was conducted in the cohort where the oldest person studied was 35 years of age. The study needs to be extended to older age groups as well. A bias that using the cohort has introduced in the study is the survival bias, as those who had been lost due to mortality and migration were missed out in the study, and these individuals may have had more severe (in case of those who died) or variable severity (in case of those who migrated) disease.

\section{Conclusions}

This study confirms the fact that SCD is a chronic disease where the prevalence of depression and loneliness increases to higher levels than in the general population. The depressive symptoms in this population show significant association with demographic variables such as educational status, and employment. Health care professionals working with the SCD population need to be aware of these factors. They need to ensure continuing education of the patients, and hence increase further their ability to have worthwhile employment. These factors need to be at the forefront of all health surveillance visits from childhood. Even though a myriad of studies have shown that chronic diseases often co-exist with depression, sadly this evidence has not translated into practice [47], as these feelings of depression, anxiety etc. may be trivialized or ignored in the bigger picture of managing the 'main' illness. Co-existing depression needs to be diagnosed and managed optimally for total biopsychosocial care of the patient, especially as there appears to be a bi-directional relationship between depression and many medical illnesses.

Chronic complications such as frequent painful crises and leg ulcers, which in turn increase healthcare utilization by those with these complications, are also issues that need to be recognized. More effective pain relief would no doubt benefit those with depression. Conversely, having concurrent depression may worsen pain, and so use of antidepressants may be considered beneficial as adjunct therapy in pain management.

\section{Authors' contributions}

MA contributed to study design, data collection, analysis and manuscript preparation; RF contributed to study design and data analysis; NL contributed to data collection and final manuscript preparation; MR contributed to design, data collection, analysis and manuscript preparation. All authors have read and approved the final manuscript.

\section{Competing interests}

The authors declare that they have no competing interests.

Received: 22 October 2009 Accepted: 7 June 2010

Published: 7 June 2010

\section{References}

1. Serjeant G, Serjeant B: Nomenclature and genetics of Sickle Cell Disease. Sickle Cell Disease Oxford: Oxford University PressSerjeant G, Serjeant B , 3 2001, 31-40.

2. Nesse RE, Finlayson RE: Management of depression in patients with coexisting medical illness. Am Fam Physician 1996, 53:2125-2133.

3. Patten SB, Beck CA, Kassam A, Williams JV, Barbui C, Metz LM: Long-term medical conditions and major depression: strength of association for specific conditions in the general population. Can J Psychiatry 2005, 50:195-202.

4. Chapman DP, Perry GS, Strine TW: The vital link between chronic disease and depressive disorders. Prev Chronic Dis 2005, 2:A14 
5. Hasan SP, Hashmi S, Alhassen M, Lawson W, Castro O: Depression in sickle cell disease. J Natl Med Assoc 2003, 95:533-537.

6. Molock SD, Belgrave FZ: Depression and anxiety in patients with sickle cell disease: conceptual and methodological considerations. J Health Soc Policy 1994, 5:39-53.

7. Udofia O, Oseikhuemen AE: Psychiatric morbidity in patients with sickle cell anaemia. West Afr J Med 1996, 15:196-200.

8. Wilson Schaeffer JJ, Gil KM, Burchinal M, Kramer KD, Nash KB, Orringer E, Strayhorn D: Depression, disease severity, and sickle cell disease. J Behav Med 1999, 22:115-126.

9. Jenerette C, Funk M, Murdaugh C: Sickle cell disease: a stigmatizing condition that may lead to depression. Issues Ment Health Nurs 2005, 26:1081-1101.

10. Levenson JL, McClish DK, Dahman BA, Bovbjerg VE, de ACV, Penberthy LT, Aisiku IP, Roberts JD, Roseff SD, Smith WR: Depression and anxiety in adults with sickle cell disease: the PiSCES project. Psychosom Med 2008, 70:192-196.

11. Hilton C, Osborn M, Knight S, Singhal A, Serjeant G: Psychiatric complications of homozygous sickle cell disease among young adults in the Jamaican Cohort Study. Br J Psychiatry 1997, 170:69-76.

12. Hays RD, DiMatteo MR: A short-form measure of loneliness. J Pers Assess 1987, 51:69-81.

13. Weiss RS: Separation and other problems that threaten relationships. Bmj 1998, 316:1011-1013.

14. DiTomasso E, Brannen C, Best LA: Measurement and validity chracteristics of the short version of the Social and Emotional loneliness scale for adults. Educational and Psychological Measurement 2004, 64:99-119.

15. Beal CC, Stuifbergen A: Loneliness in women with multiple sclerosis. Rehabil Nurs 2007, 32:165-171.

16. Kara M, Mirici A: Loneliness, depression, and social support of Turkish patients with chronic obstructive pulmonary disease and their spouses. $J$ Nurs Scholarsh 2004, 36:331-336.

17. Sevil U, Ertem G, Kavlak O, Coban A: The loneliness level of patients with gynecological cancer. Int I Gynecol Cancer 2006, 16(Suppl 1):472-477.

18. Luanaigh CO, Lawlor BA: Loneliness and the health of older people. Int J Geriatr Psychiatry 2008, 23:1213-1221.

19. Mahon NE, Yarcheski A, Yarcheski TJ, Cannella BL, Hanks MM: A metaanalytic study of predictors for loneliness during adolescence. Nurs Res 2006, 55:308-315.

20. Adams $K B$, Sanders $S$, Auth EA: Loneliness and depression in independent living retirement communities: risk and resilience factors. Aging Ment Health 2004, 8:475-485.

21. Ohaeri JU, Shokunbi WA, Akinlade KS, Dare LO: The psychosocial problems of sickle cell disease sufferers and their methods of coping. Soc Sci Med 1995, 40:955-960.

22. Grothe KB, Dutton GR, Jones GN, Bodenlos J, Ancona M, Brantley PJ: Validation of the Beck Depression Inventory-ll in a low-income African American sample of medical outpatients. Psychol Assess 2005, 17:110-114.

23. Whisman MA, Perez JE, Ramel W: Factor structure of the Beck Depression Inventory-Second Edition (BDI-II) in a student sample. J Clin Psychol 2000, 56:545-551.

24. Steer RA, Ball R, Ranieri WF, Beck AT: Further evidence for the construct validity of the Beck depression Inventory-II with psychiatric outpatients. Psychol Rep 1997, 80:443-446.

25. Lipps GE, Lowe GA, Young R: Validation of the beck depression inventory-II in a Jamaican university student cohort. West Indian Med J 2007, 56:404-408.

26. Russell D, Peplau LA, Ferguson ML: Developing a measure of loneliness. J Pers Assess 1978, 42:290-294.

27. Russell D, Peplau LA, Cutrona CE: The revised UCLA Loneliness Scale: concurrent and discriminant validity evidence. J Pers Soc Psychol 1980 39:472-480.

28. Russell DW: UCLA Loneliness Scale (Version 3): reliability, validity, and factor structure. J Pers Assess 1996, 66:20-40.

29. Hartshorne TS: Psychometric properties and confirmatory factor analysis of the UCLA loneliness scale. J Pers Assess 1993, 61:182-195.

30. Oshagan H, Allen RL: Three loneliness scales: an assessment of their measurement properties. J Pers Assess 1992, 59:380-409.

31. Jones WH, Quintana D, BN C: Personality and Interpersonal Predictors of Loneliness in Two Cultures. Journal of Personality and Social Psychology 1985, 48:1503-1511.
32. Wilson D, Cutts J, Lees I, Mapungwana S, Maunganidze L: Psychometric properties of the revised UCLA Loneliness Scale and two short-form measures of loneliness in Zimbabwe. J Pers Assess 1992, 59:72-81.

33. Beck AT, Guth D, Steer RA, Ball R: Screening for major depression disorders in medical inpatients with the Beck Depression Inventory for Primary Care. Behav Res Ther 1997, 35:785-791.

34. Harris CA, D'Eon JL: Psychometric properties of the Beck Depression Inventory-second edition (BDI-II) in individuals with chronic pain. Pain 2008, 137:609-622

35. Ward E: A Review of Hospital care: Outlining morbidity and mortality patterns, cost of care \& resource inputs. Kingston, Jamaica 1996.

36. Cacioppo JT, Hughes ME, Waite LJ, Hawkley LC, Thisted RA: Loneliness as a specific risk factor for depressive symptoms: cross-sectional and longitudinal analyses. Psychol Aging 2006, 21:140-151.

37. Berkman LF, Syme SL: Social networks, host resistance, and mortality: a nine-year follow-up study of Alameda County residents. Am J Epidemiol 1979, 109:186-204.

38. House JS, Robbins C, Metzner HL: The association of social relationships and activities with mortality: prospective evidence from the Tecumseh Community Health Study. Am J Epidemiol 1982, 116:123-140.

39. Cacioppo JT, Hawkley LC, Crawford LE, Ernst JM, Burleson MH, Kowalewski RB, Malarkey WB, Van Cauter E, Berntson GG: Loneliness and health: potential mechanisms. Psychosom Med 2002, 64:407-417.

40. Kiecolt-Glaser JK, Ricker D, George J, Messick G, Speicher CE, Garner W, Glaser R: Urinary cortisol levels, cellular immunocompetency, and loneliness in psychiatric inpatients. Psychosom Med 1984, 46:15-23.

41. Laurence B, George D, Woods D: Association between elevated depressive symptoms and clinical disease severity in African-American adults with sickle cell disease. I Natl Med Assoc 2006, 98:365-369.

42. Belgrave FZ, Molock SD: The role of depression in hospital admissions and emergency treatment of patients with sickle cell disease. J Natl Med Assoc 1991, 83:777-781.

43. Cumming V, King L, Fraser R, Serjeant G, Reid M: Venous incompetence, poverty and lactate dehydrogenase in Jamaica are important predictors of leg ulceration in sickle cell anaemia. Br J Haematol 2008, 142:119-125.

44. Alleyne SI, Wint E, Serjeant GR: Social effects of leg ulceration in sickle cell anemia. South Med J 1977, 70:213-214.

45. Thompson RJ Jr, Gil KM, Abrams MR, Phillips G: Stress, coping, and psychological adjustment of adults with sickle cell disease. J Consult Clin Psychol 1992, 60:433-440.

46. Richter P, Werner J, Heerlein A, Kraus A, Sauer H: On the validity of the Beck Depression Inventory. A review. Psychopathology 1998, 31:160-168.

47. Evans DL, Charney DS, Lewis L, Golden RN, Gorman JM, Krishnan KR, Nemeroff CB, Bremner JD, Carney RM, Coyne JC, et al: Mood disorders in the medically ill: scientific review and recommendations. Biol Psychiatry 2005, 58:175-189.

\section{Pre-publication history}

The pre-publication history for this paper can be accessed here: http://www.biomedcentral.com/1471-244X/10/40/prepub

\section{doi:10.1186/1471-244X-10-40}

Cite this article as: Asnani et al:: Depression and loneliness in Jamaicans with sickle cell disease. BMC Psychiatry 2010 10:40.

\section{Submit your next manuscript to BioMed Central and take full advantage of:}

- Convenient online submission

- Thorough peer review

- No space constraints or color figure charges

- Immediate publication on acceptance

- Inclusion in PubMed, CAS, Scopus and Google Scholar

- Research which is freely available for redistribution 